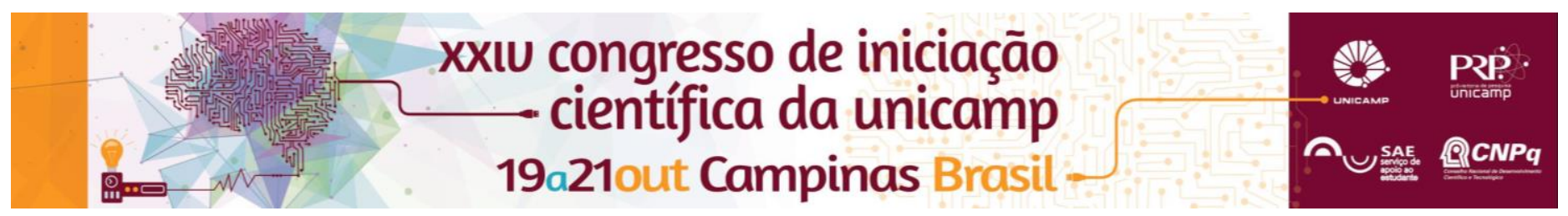

\title{
Modernos e Brasileiros: o diálogo do Brasil Arquitetura com o trabalho de Lina Bo Bardi e Lucio Costa
}

\section{Luana Espig Regiani, Silvana Barbosa Rubino.}

\section{Resumo}

$\mathrm{Na}$ arquitetura brasileira, Lina Bo Bardi e Lucio Costa são referências que extrapolam períodos e chegam ao presente, onde está o Brasil Arquitetura. Buscando compreender essa relação, foram feitas viagens de estudo, maquetes e entrevistas. A pesquisa permitiu perceber como Francisco Fanucci e Marcelo Ferraz realizam uma arquitetura que mantém o diálogo com aqueles que são parte importante na construção das ações dos arquitetos e como consideram a cultura local ao trabalhar questões universais.

\section{Palavras-chave:}

Brasil Arquitetura, Lina Bo Bardi, Lucio Costa.

\section{Introdução}

A obra de um escritório de arquitetura pode ser vista através de posturas e referências que de forma recorrente estão presentes nos projetos. Quando o assunto é arquitetura brasileira, pode-se pensar que ela estabelece seus referenciais tanto na história colonial e na experiência vernacular dos seus habitantes, quanto nos precursores modernos nacionais e internacionais. Refletindo sobre essas questões, podemos perceber no escritório Brasil Arquitetura uma obra rara. Neste contexto, busca-se analisar o Brasil Arquitetura sob a ótica daqueles que julgamos ser parte importante na construção dos alicerces do escritório: Lina Bo Bardi e Lucio Costa.

Para compreender como essas conversas atuam em um escritório contemporâneo, procura-se estabelecer convergências no trabalho dos arquitetos ao realizarem suas obras, sejam escritas, desenhadas ou construídas.

\section{Resultados e Discussão}

"Buscamos em Lucio Costa o que ele filtrou e depurou da arquitetura do Brasil colônia e, em Lina, sua capacidade de atuar em múltiplas disciplinas, sem se submeter ao tempo linear histórico, e nem às limitações geográficas." ".

Para encontrar as diversas linhas de diálogo do Brasil Arquitetura com Lucio Costa e Lina Bo Bardi, a pesquisa buscou permear o saber e o fazer arquitetônico do trabalho dos arquitetos. A metodologia adotada se mostrou essencial para uma compreensão multissensorial. Além da revisão bibliográfica, foram feitas visitas de campo em projetos selecionados, vivenciando-os em diferentes contextos brasileiros, passando pela Bahia, São Paulo e Rio Grande do Sul. As viagens tiveram como resultado a produção de um diário, com registros escritos e desenhados. Outro ponto fundamental foram as entrevistas com os arquitetos fundadores do Brasil Arquitetura, fora a contribuição direta para a Iniciação Científica, a transcrição das mesmas pode colaborar com futuros estudos. Também fez parte da metodologia, a construção de maquetes representando as diferentes escalas de atuação do Brasil Arquitetura e a análise destes projetos dentro do tema estudado. $O$ trabalho desenvolvido está em uma monografia, disponível em meio digital, onde buscou-se traduzir gráfica e textualmente a experiência proporcionada pela imersão na pesquisa.

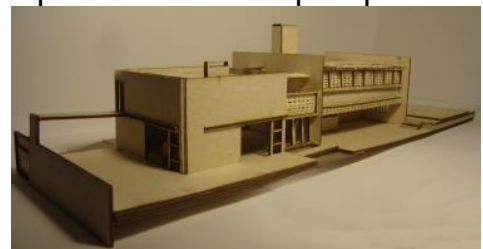

Figura 1. Casa Ubiracica, maquete desenvolvida na IC

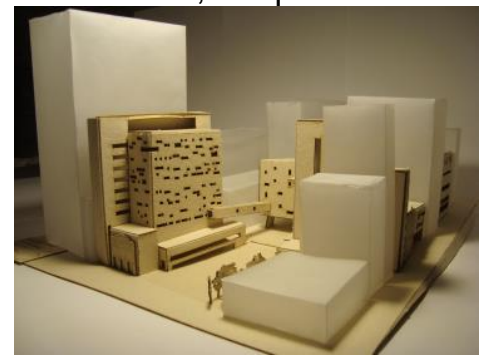

Figura 2. Praça das Artes, maquete desenvolvida na IC Conclusões

Lina Bo Bardi e Lucio Costa são alicerces da arquitetura brasileira, através deles pode-se perceber encaminhamentos arquitetônicos que extrapolam o Moderno e chegam ao presente. Neste presente está o Brasil Arquitetura e suas conversas. Francisco Fanucci e Marcelo Ferraz absorvem, digerem e transformam influências externas, respeitando e estabelecendo conexões com a memória, a cultura local e seus protagonistas. Assim, os projetos propõem soluções a demandas humanas universais de relacionamento e comunicação, mas considerando uma maneira própria de estar no mundo que busca no país de origem a matéria-prima do trabalho. Realizam uma arquitetura brasileira contemporânea, mantendo o diálogo com aqueles que são parte importante na construção das ações dos arquitetos: Lina Bo Bardi e Lucio Costa.

\section{Agradecimentos}

Agradeço à Silvana Rubino, por abraçar o tema desde a primeira conversa, à Eloiza Espig, apoio constante em todos os projetos, e à FAPESP Fundação de Amparo à Pesquisa do Estado de São Paulo, pelo incentivo à pesquisa.

\footnotetext{
1 FERRAZ, Marcelo Carvalho. Arquitetura Conversável. Rio de Janeiro:
} Azougue Editorial, 2011. p.30. 